\title{
Accuracy assessment of cadastral maps using high resolution aerial photos
}

\author{
Imzahim Alwan ${ }^{1, *}$, Noor Hamed ${ }^{1}$ and Haifaa Husien ${ }^{1}$ \\ ${ }^{1}$ Building and Construction Engineering Department, University of Technology, Baghdad, Iraq
}

\begin{abstract}
A cadastral map is a map that shows the boundaries and ownership of land parcels. Some cadastral maps show additional details, such as survey district names, unique identifying numbers for parcels, certificate of title numbers, positions of existing structures, section or lot numbers and their respective areas, adjoining and adjacent street names, selected boundary dimensions and references to prior maps. In Iraq / Baghdad Governorate, the main problem is that the cadastral maps are georeferenced to a local geodetic datum known as Clark 1880 while the widely used reference system for navigation purpose (GPS and GNSS) and uses Word Geodetic System 1984 (WGS84) as a base reference datum. The objective of this paper is to produce a cadastral map with scale 1:500 (metric scale) by using aerial photographs 2009 with high ground spatial resolution $10 \mathrm{~cm}$ reference WGS84 system. The accuracy assessment for the cadastral maps updating approach to urban large scale cadastral maps (1:500-1:1000) was $\mp 0.115$ meters; which complies with the American Social for Photogrammetry and Remote Sensing Standards (ASPRS).
\end{abstract}

\section{Introduction}

The cadastre is one of the most important country's registers which shows individual cadastral units of parcels and land ownership [1]. The Cadastre is a methodology arranged for public inventory of data concerning properties within a district based on survey of their boundaries; these boundaries are shown on large scale maps [2].

The urban area in all countries has witnessed many changes in terms of urbanization and growth of population. Because of the daily changes in an urban area, updating cadastral maps can be considered as continuous problem with no end. Those cadastral maps were required to be updated but no updating was carried out in last five to six decades. Consequently, the cadastral maps in Iraq are out of today's development and are unable to serve the urban requirements. Maps in Iraq/ Baghdad Governorate are largely out dated and don't reflect the realities of the ground.

Iraq's maps referenced to Clark 1866 which was the first local geodetic system accomplished during 1930s. The Iraqi cadastral maps were referenced to this system. In 1967 a new system called English system or Nahrwan 67 appeared and was referenced to Clark 1880[3].

In Iraq specifically in Baghdad city, the existing cadastral maps produced for the center of Baghdad only by the Union of Surveying and Cartographic Enterprises of Poland represented by (Pole Service) between 19741979 with scale 1:500 [4]. The coordinates for these cadastral maps have been computed in UTM Universal Transfer Mercator System on Clark 1880 ellipsoid. The

\footnotetext{
*Corresponding author: 40164@uotechnology.edu.iq
}

point where the ellipsoid coincides with the geoid is Karbala 79 [4]. Clark ellipsoid 1880 was designed to fit the shape of Iraq, this employed as a local coordinate system. There is a shift between Clark 1880/ Karbala 79 datum and WGS84 because of the difference between local and geocentric datum [3].

\section{Study Area}

The study area is a Neighborhood No.512 located inside the boundary of Baghdad Municipality (Sadr City). This neighborhood has a rectangular shape, as shown in Figure1.

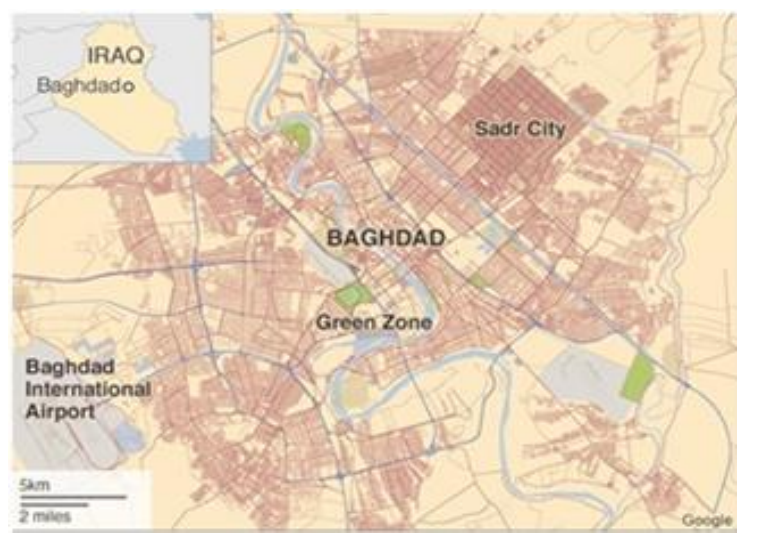

Fig. 1. Baghdad municipality boundary

\section{Methodologies}




\subsection{Data collection and pre-processing}

In this paper, the geospatial data sources are: twenty traditional cadastral maps represent the study area, the map scale is1:500 as shown in Figure 2, with their index as shown in Table 1. These maps were obtained from Baghdad Municipality the main official office deals with urban cadastral maps that were carried by Pole Service Company. The datum of these maps is Clark 1880/ Karbala79.

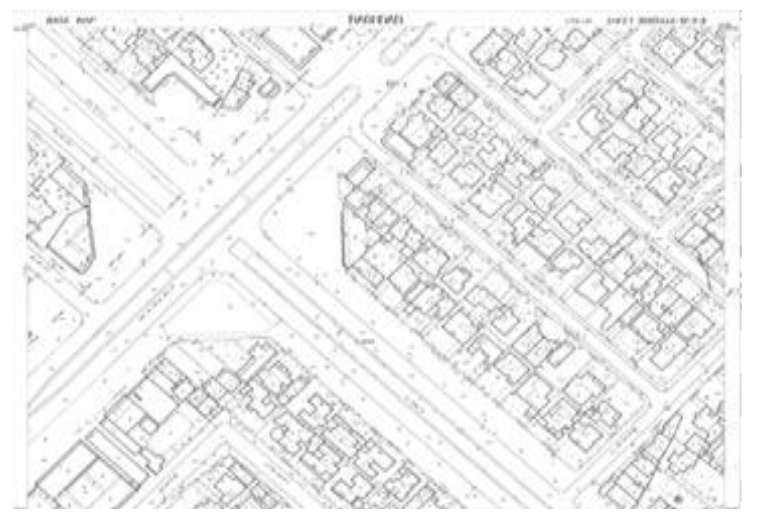

Fig. 2. Traditional cadastral map

Table 1. Index of traditional cadastral maps

\begin{tabular}{|c|c|c|}
\hline No. & $\begin{array}{c}\text { Index of } \\
\text { map }\end{array}$ & Map code \\
\hline 1 & $3690-444$ & $18-3-1$ \\
\hline 2 & $3690-444$ & $17-2-1$ \\
\hline 3 & $3690-444$ & $17-2-3$ \\
\hline 4 & $3690-444$ & $17-2-4$ \\
\hline 5 & $3690-444$ & $17-1-2$ \\
\hline 6 & $3690-444$ & $17-1-4$ \\
\hline 7 & $3690-444$ & $17-4-1$ \\
\hline 8 & $3690-444$ & $17-4-2$ \\
\hline 9 & $3690-444$ & $17-4-4$ \\
\hline 10 & $3690-444$ & $12-3-1$ \\
\hline 11 & $3690-444$ & $12-3-2$ \\
\hline 12 & $3690-444$ & $12-3-3$ \\
\hline 13 & $3690-444$ & $12-3-4$ \\
\hline
\end{tabular}

The aerial photo captured in 2009 with ground sample distance (GSD) of $10 \mathrm{~cm}$ considered as base map as shown in figure 3. This photo was geo-rectified to WGS84 UTM coordinate system. Five ground control points were selected to measure through used DGPS. These five control points were used to generate coefficients for first order polynomial and a nearest neighbor method was applied to resample the photo. The root mean square errors were found to be less than 0.4 pixels. The preprocessing was applied by using ERDAS 9.0 and ArcGIS 9.2 software; Table (2) shows the first order polynomial coefficients; Table (3) shows the coordinates of ground control points.

\begin{tabular}{|l|c|c|c|}
\hline $\boldsymbol{a}_{\mathbf{1}}$ & 9.996679716 & $\boldsymbol{b}_{\mathbf{1}}$ & -0.000855515 \\
\hline $\boldsymbol{a}_{\mathbf{2}}$ & -0.009542856 & $\boldsymbol{b}_{\mathbf{2}}$ & 10.00421759 \\
\hline
\end{tabular}

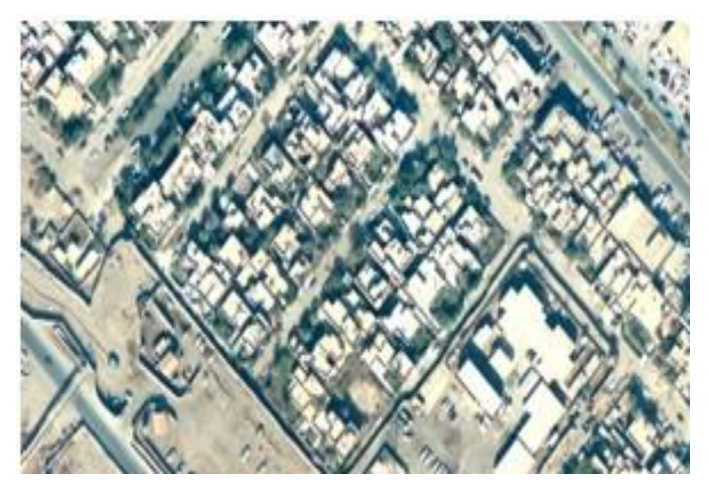

Fig. 3. The aerial photo of Baghdad city/neighborhood No.512

\subsection{Digitizing}

An aerial photo represents the basic reference for the data which is required for updating urban cadastral maps, because of the fact that the photo represents the current reality of all existing artificial man- made features. Consequently, the aerial photo represents the best reference for detecting and checking any changing that might happen [6].A photomap was produced from the aerial photo, The photomap would be considered as a base map and consisted of all characteristics of base map, then this base map can be used as a reference map to update the cadastral maps. The digitizing process of the map features was carried using ArcGIS9.2 software. The updated maps for the Neighborhood No.512 have been developed according to projection WGS84 UTM because of the fact that the map was produced using ArcGIS 9.2 software base on the aerial photo as shown in Figure 4.

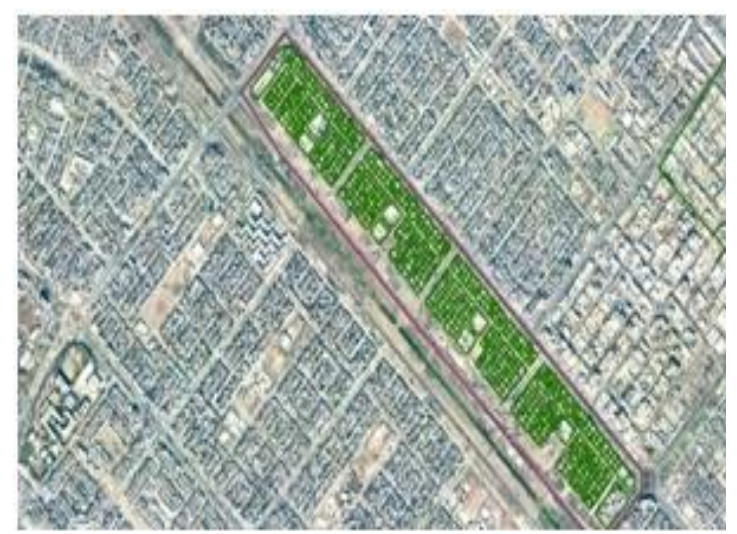

Fig. 4. The updating maps of neighborhood No.512

Table 2.1st Order Polynomial Coefficients

\begin{tabular}{|l|l|l|l|}
\hline $\boldsymbol{a}_{\mathbf{0}}$ & -4434970.826 & $\boldsymbol{b}_{\mathbf{0}}$ & -36882532.76 \\
\hline
\end{tabular}


TABLE 3. Coordinates of ground control points

\begin{tabular}{|c|c|c|c|c|c|c|c|c|}
\hline $\begin{array}{c}\text { GCP } \\
\text { No. }\end{array}$ & Longitude & Latitude & $\begin{array}{c}\text { Easting } \\
(\mathbf{m})\end{array}$ & $\begin{array}{c}\text { Northing } \\
(\mathbf{m})\end{array}$ & $\begin{array}{c}\text { X- } \\
\text { Residual } \\
(\mathbf{m})\end{array}$ & $\begin{array}{c}\text { Y- } \\
\text { Residual } \\
(\mathbf{m})\end{array}$ & $\begin{array}{c}\text { RMSE } \\
(\mathbf{m})\end{array}$ & $\begin{array}{c}\text { Ellipsoid } \\
\text { Height } \\
(\mathbf{m})\end{array}$ \\
\hline 1 & $44^{\circ} 26^{\prime} 37.725^{\prime \prime}$ & $33^{\circ} 18^{\prime} 41.707^{\prime \prime}$ & 448226.347 & 3685968.217 & -0.203 & -0.790 & 0.816 & 31.114 \\
\hline 2 & $44^{\circ} 26^{\prime} 57.938^{\prime \prime}$ & $33^{\circ} 18^{\prime} 19.016^{\prime \prime}$ & 448745.340 & 3685266.604 & -0.154 & -0.045 & 0.161 & 31.822 \\
\hline 3 & $44^{\circ} 26^{\prime} 18.489^{\prime \prime}$ & $33^{\circ} 18^{\prime} 52.072^{\prime \prime}$ & 447730.683 & 3686290.066 & -0.017 & 0.407 & 0.407 & 31.563 \\
\hline 4 & $44^{\circ} 26^{\prime} 12.149^{\prime \prime}$ & $33^{\circ} 18^{\prime} 41.485^{\prime \prime}$ & 447564.978 & 3685964.887 & -0.155 & 0.078 & 0.173 & 31.687 \\
\hline 5 & $44^{\circ} 27^{\prime} 08.435^{\prime \prime}$ & $33^{\circ} 18^{\prime} 26.750^{\prime \prime}$ & 449018.029 & 3685503.370 & -0.220 & 0.350 & 0.413 & 31.821 \\
\hline
\end{tabular}

\subsection{Geo-referencing}

The principles of manual Georeferencing of traditional cadastral maps and aerial photo have been used through the selection of a number of well-defined features in the cadastral maps as well as the aerial photo. The coordinates in a cadastral map are representing the source and the coordinates of an aerial photo are the reference. Minimum twenty (20) points were used in georeference processes. The Georeferencing takes into consideration the resultant updating map would have the optimum precision through the application of weighting system to the maps through which starting with the higher weight map and then gradually done to the lowest weight map. The problem was that there were no tied points connect between the maps as there was between photos, therefore, to reduce the edge demerges between twenty maps covering the neighborhood the weighting system was used. This system depends on the number of surrounding maps. There are four types of different weights $(4,3,2$, and 1$)$ as illustrated in Table 4.

TABLE 4.Maps weighting

\begin{tabular}{|c|c|c|}
\hline $\begin{array}{c}\text { Index of } \\
\text { map }\end{array}$ & Map number & weight \\
\hline $3690-444$ & $12-3-1$ & 2 \\
\hline $3690-444$ & $12-3-2$ & 2 \\
\hline $3690-444$ & $12-3-3$ & 2 \\
\hline $3690-444$ & $12-3-4$ & 3 \\
\hline $3690-444$ & $17-1-2$ & 2 \\
\hline $3690-444$ & $18-3-1$ & 1 \\
\hline $3690-444$ & $17-2-1$ & 2 \\
\hline $3690-444$ & $17-2-3$ & 4 \\
\hline $3690-444$ & $17-2-4$ & 2 \\
\hline $3690-444$ & $17-4-1$ & 2 \\
\hline $3690-444$ & $17-4-2$ & 4 \\
\hline $3690-444$ & $17-4-4$ & 1 \\
\hline
\end{tabular}

The map has higher weight 4 with map index 17-2-3 that is surrounded by other four maps. The georeference of this map through the use of a minimum twenty (20) of well-defined features (points) which were represented by houses sides and streets, taking into consideration that those points must be well distributed on the map which must include a minimum of two points on each side closed to edge boundaries of the map to avoid rotation and translation as shown in Figure 5 and the result of georeferenced map illustrated in Table 6. The map index 17-4-2 was georeferenced by the same approach.
All maps having a weight equal to three then two and finally one have been georeferenced. The Georeferencing between communed edges of maps was done by selecting more than two well-defined features in common edge then choosing a number of well distributed points inside. The well-defined features must be presented first by house- sides and then by street, therefore the priority should be given to the houses and then the streets. The final results of all georeferenced maps are shown in Figure 6 and TRMS obtained is listed in Table 5.

Table 5. TRMS of twenty maps

\begin{tabular}{|c|c|c|c|}
\hline $\begin{array}{c}\text { Map } \\
\text { index }\end{array}$ & TRMS & Map index & TRMS \\
\hline $17-2-3$ & 0.26560 & $17-1-2$ & 0.20488 \\
\hline $17-4-2$ & 0.10217 & $12-3-3$ & 0.25965 \\
\hline $12-3-4$ & 0.25861 & $12-3-2$ & 0.19990 \\
\hline $17-2-4$ & 0.24099 & $12-3-1$ & 0.25528 \\
\hline $17-4-1$ & 0.24910 & $18-3-1$ & 0.22448 \\
\hline $17-2-1$ & 0.30271 & $17-4-4$ & 0.14207 \\
\hline
\end{tabular}

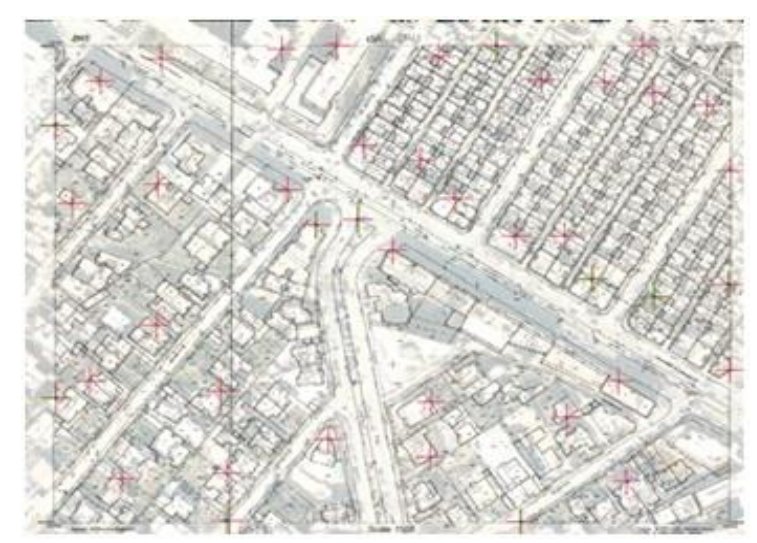

Fig. 5. Georeferencing of map 17-2-3 


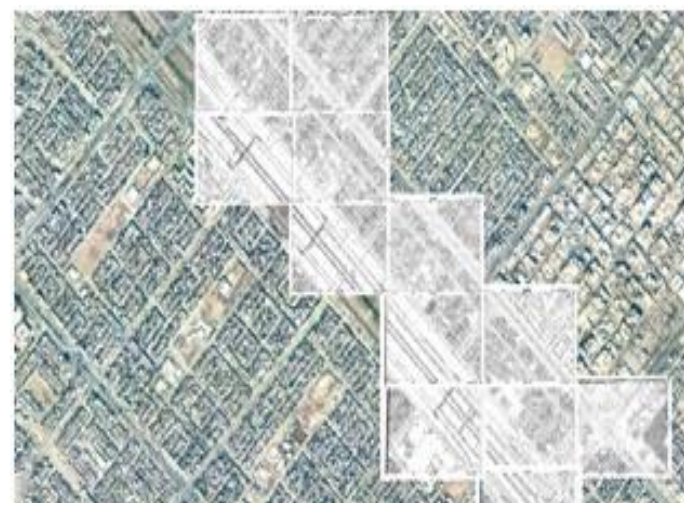

Fig. 6. Georeferencing maps of neighborhood No.512

Table 6.Georeferencing results of map 17-2-3

\begin{tabular}{|c|c|c|c|c|}
\hline $\begin{array}{c}\text { Point } \\
\text { ID }\end{array}$ & $\begin{array}{c}\text { X- } \\
\text { source }\end{array}$ & $\begin{array}{c}\text { Y- } \\
\text { source }\end{array}$ & $\begin{array}{c}\text { X- } \\
\text { reference }\end{array}$ & $\begin{array}{c}\text { Y- } \\
\text { reference }\end{array}$ \\
\hline 1 & 448800.631 & 3685662.745 & 448512.315 & 3685943.020 \\
\hline 2 & 449104.752 & 3685508.320 & 448812.780 & 3685786.700 \\
\hline 3 & 449090.173 & 3685684.775 & 448801.830 & 3685963.740 \\
\hline 4 & 448996.087 & 3685698.916 & 448707.837 & 3685978.055 \\
\hline 5 & 448800.041 & 3685784.979 & 448510.620 & 3686065.456 \\
\hline 6 & 449160.709 & 3685719.707 & 448872.467 & 3685198.775 \\
\hline 7 & 449146.356 & 3685638.059 & 448858.806 & 3685917.078 \\
\hline 8 & 449001.690 & 3685517.155 & 448714.320 & 3685795.711 \\
\hline 9 & 449159.978 & 3685538.385 & 448873.025 & 3685816.778 \\
\hline 10 & 449048.668 & 3685696.912 & 448760.349 & 3685926.341 \\
\hline 11 & 448966.495 & 3685500.085 & 448678.754 & 3685778.699 \\
\hline 12 & 449073.118 & 3615523.063 & 448785.877 & 3685801.478 \\
\hline 13 & 449060.950 & 3685505.740 & 448775.891 & 3685784.104 \\
\hline 14 & 449104.752 & 3685508.320 & 448812.780 & 3685786.700 \\
\hline 15 & 449122.141 & 3685213.045 & 448834.987 & 3685491.277 \\
\hline 16 & 449194.942 & 3685226.979 & 448907.497 & 3685505.692 \\
\hline 17 & 449162.067 & 3685256.652 & 448874.591 & 3685535.250 \\
\hline 18 & 449108.489 & 3685200.747 & 447721.009 & 3685479.338 \\
\hline 19 & 449198.800 & 3685362.449 & 448911.995 & 3685641.515 \\
\hline 20 & 449146.749 & 3685499.879 & 448859.364 & 3685776.905 \\
\hline
\end{tabular}

\section{Precision assessments}

Unfortunately most if not all the literature uses the term accuracy and true value, since as a matter of fact nobody can determine the true value of any measurement at all. For this reason, we are actually dealing with the precision and not the accuracy, as well as the most probable value and not the true value [5].

The Planimetric accuracy of the land parcels was carried out by comparing length and area of selected plot boundaries from aerial photo with in-situ field observations using total station and field measurement parcel [6]. The accuracy of field boundaries prepared from the image was validated by the following method.

Different existing houses have been chosen randomly in Neighborhood No.512; the length of seven well defined side of these houses in the photomap and field survey used (EDM) Electronical Distance Measurement has been measured as shown in Table 7, RMSE wasథ0.115 m.
Table 7. Precision assessment

\begin{tabular}{|c|c|c|c|}
\hline $\begin{array}{c}\text { House } \\
\text { No. }\end{array}$ & $\begin{array}{c}\text { Ground } \\
\text { Distance } \\
(\mathbf{m})\end{array}$ & $\begin{array}{c}\text { Map } \\
\text { Distance } \\
(\mathbf{m})\end{array}$ & $\begin{array}{c}\text { Difference between } \\
\text { map and Ground } \\
\text { Distance (m) }\end{array}$ \\
\hline 1 & 11.333 & 11.211 & -0.093 \\
\hline 2 & 22.944 & 23.054 & 0.110 \\
\hline 3 & 22.645 & 22.525 & -0.120 \\
\hline 4 & 6.452 & 6.552 & 0.100 \\
\hline 5 & 11.537 & 11.640 & 0.100 \\
\hline 6 & 23.184 & 23.053 & -0.131 \\
\hline 7 & 22.935 & 23.136 & 0.201 \\
\hline
\end{tabular}

\section{Results and conclusion}

Cadastral map with scale 1:500 (metric scale) was produced using aerial photo 2009 has a resolution $10 \mathrm{~cm}$ with a WGS84 system as shown in Figure7. A precision assessment of the updating approach for Urban Large Scale Cadastral Maps (1:500-1:1000) was $\mp 0.115 \mathrm{~m}$ which complies with the American Society for Photogrammetry and Remote Sensing Standards (ASPRS) [7].

The originality of this research is through use of the old cadastral maps and the new aerial images with high resolution $(10 \mathrm{~cm})$ to update and produce the cadastral maps with sufficient map scale $1 / 500$.

The ArcGIS and ERDAS software were used in the updation of cadastral updated maps methodology. 


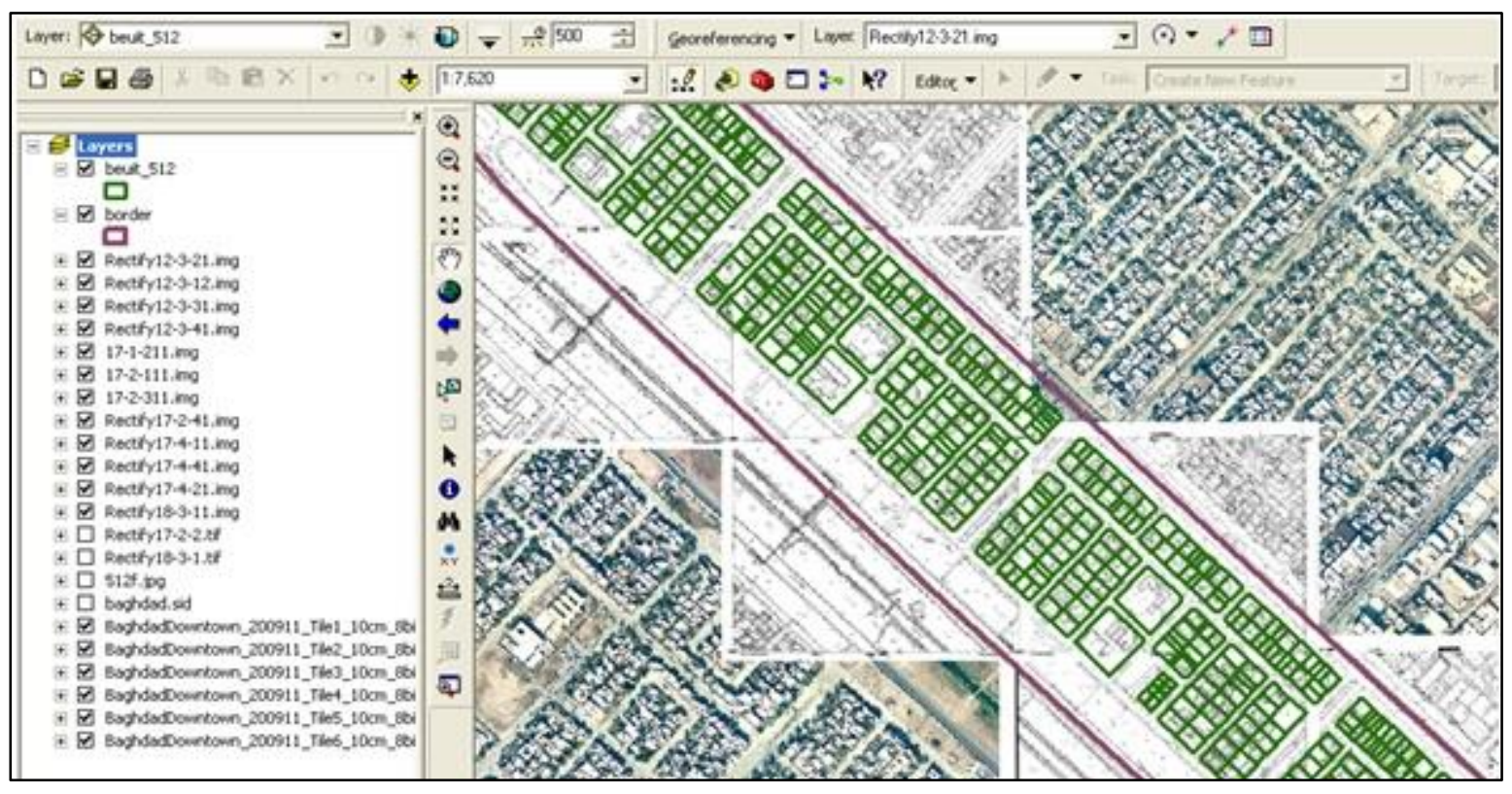

Fig. 7. ArcGIS cadastral maps

\section{References}

1. W. Effenberg, Spatial Cadastral Information Systems themaintenance of digital cadastral map, Doctorate thesis ,(Univercity of Melbourne, Department of Geomatics, 2001).

2. P.M. Brown and D. Divid Moyer, . Multipurpose Land Information Systems, (The GuideBook, The Federal Geodetic Control Committee, 1989).

3. J.Gazdzicki, H. Kwiatkowshi, New Geodeticcontrol Network In Iraq: Desgin, Surveys, And Data Processing, (Geokart -Poland. 1977)

4. A. Jaronski, R. Pazus.,. The Measurment of Geodetic Control In Republic Of Iraq, State Enterprise for Survey and Cartography, (Warszawa, Jasns 2/4 ,Poland. 1976).

5. J.M. Anderson and E.M. Mikhail,.Surveying Theory and Practice, (WCB McGraw-Hill, $7^{\text {th }}$ Edition 1998)

6. S. Kay, P. Spruyt, and K. Alexandrou,. Geometric Quality Assessment of Orthorectified VHR Space Image Data. Photogrammetric Eng. and Remote Sensing, 69, 484,(2003).

7. ASPRS .Positional Accuracy Standards for Digital Geospatial Data. Photogrammetric Engineering \& Remote Sensing Vol. 81, A26,( 2015) 